\title{
SIDE STRUCTURE INTEGRITY RESEARCH FOR PASSENGER RAIL EQUIPMENT
}

\author{
Shaun Eshraghi \\ Michael Carolan \\ A. Benjamin Perlman \\ Volpe National Transportation Systems Center \\ U.S. Department of Transportation \\ Cambridge, MA, USA
}

\section{ABSTRACT}

The U.S. Department of Transportation (DOT) Federal Railroad Administration (FRA) began promulgating regulations for the structural crashworthiness of passenger rail equipment at 49 Code of Federal Regulations (CFR) Part 238 on May 12, 1999. These Passenger Equipment Safety Standards (PESS) [1] include requirements affecting the designs of sidewall structures on passenger rail equipment. The FRA's Office of Research, Development and Technology and the DOT's Volpe National Transportation Systems Center are conducting research to evaluate the side impact strength of Tier I passenger rail equipment designs that have been constructed according to the current side structure regulations in §238.215 and §238.217.

Following a fatal 2011 accident in which a highway semitrailer truck impacted the side of a passenger train that was transiting a grade crossing in Miriam, NV, the National Transportation Safety Board (NTSB) recommended that the FRA “develop side impact crashworthiness standards (including performance validation) for passenger railcars that provide a measurable improvement compared to the current regulation for minimizing encroachment to and loss of railcar occupant survival space" [2].

This paper describes the status of the current FRA research related to side structure integrity and describes the planned next stage of the research program which will include analyzing the performance of generalized passenger railcar structures in side impact collision scenarios. A discussion of the technical challenges associated with analyzing side impacts on passenger rail equipment is also presented.

\section{INTRODUCTION}

This paper examines recently-performed research into the occupant volume integrity (OVI) of passenger rail vehicles when subjected to lateral loading. Conventional passenger railcar designs in service in the U.S. are designed to meet requirements contained within regulations promulgated by the FRA, including requirements on the design of side structures. FRA has sponsored research at the Volpe National Transportation Systems Center (Volpe) to examine the issue of side structure integrity.

As a first stage in the research program, the current state of side structure integrity was examined including: (1) the makeup of the passenger car fleet within the U.S.; (2) the accident history involving side structures within the U.S.; and (3) a review of side structure design and performance criteria contained in current standards and regulations. This approach examined how the side structure requirements have influenced the design of passenger rail vehicles, how vehicles designed to those criteria have performed in incidents, and how the current fleet compares to that which existed when the current standards and regulations were issued in 1999.

\section{CONVENTIONAL SIDEWALL DESIGNS}

The term "conventional" refers to passenger railcars that have been designed and constructed according to longstanding design practice in the U.S. for service on the U.S. general railroad system. These design practices date back well before FRA's 1999 rulemaking [3], meaning that cars constructed before 1999 might comply with the current requirements without having formally demonstrated compliance to the FRA.

The phrase "alternatively-designed" is used in this paper to describe passenger rail vehicles that were not originally designed specifically to meet the U.S. design criteria, but are operated on the U.S. general railroad system. For example, an alternativelydesigned passenger railcar may have been originally designed to operate on the European rail network, but has been granted a waiver by FRA to operate in the U.S. under specific conditions. Alternatively-designed vehicles are not designed to be compliant with the same side structure requirements as railcars of conventional U.S. design. They may be operating under an FRA waiver or they may have demonstrated alternative compliance with regulations.

This material is declared a work of the U.S. Government and is not subject to copyright protection in the United States. Approved for public release. Distribution is unlimited. 
Conventional U.S. passenger railcar designs typically feature a sidewall constructed of discrete vertical and longitudinal members with an exterior metal sheathing. In general, the vertical members of the sidewall are referred to as posts, with the most structurally-substantial sidewall post located at each corner of the occupied volume. The longitudinal member at the intersection of the sidewall and the underframe is referred to as the side sill, and can be considered a part of both the sidewall and underframe structures. In typical single-level car designs, the longitudinal members are prismatic in cross-section. The longitudinal member at the top of the sidewall is referred to as the roof rail. The sidewall also features a longitudinal member referred to as a belt rail, typically located just below the windows. A schematic of a representative single-level passenger railcar, with a cutaway indicating major structural members, is shown in Figure 1.

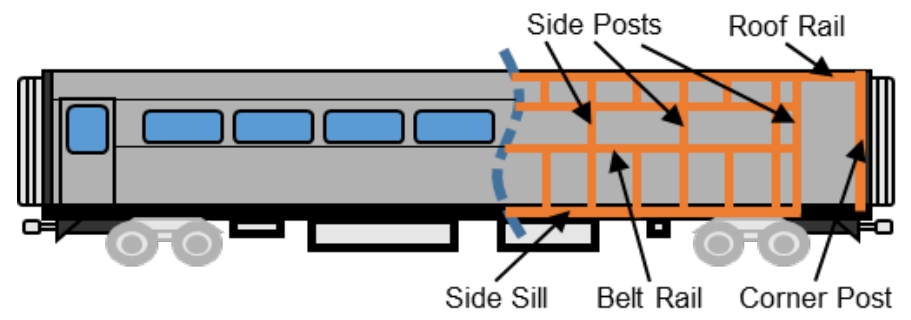

Figure 1. Generalized Sidewall Members, Single-level Conventional Railcar

In the case of a multi-level passenger railcar, the sidewall structure can be more complex owing to the need to accommodate a partial or full-length second floor within the space constraints of the railroad's clearance envelope (e.g. tunnel height, clearance between adjacent tracks). A wide variety of multi-level vehicle designs operate within the U.S. railroad system, with different sidewall structures for each design. However, in general, multi-level passenger car sidewalls can differ from single-level vehicles in several key ways.

One typical feature of a multi-level passenger car is a nonplanar underframe, owing to the need to accommodate the coupler and wheelset arrangements at the ends of the cars. The underframe transitions downward toward the center of the car to allow for standing passengers on both the lower and upper levels. This places the side sill closer to the rail in the center of the car, and increases the overall height of the sidewall.

Additionally, a multi-level passenger car will typically feature longitudinal structure in the sidewall to support the upper level. Depending on the design of the multi-level car, the upper level may only extend over the region of the car where the underframe has transitioned downward, or may extend for the full-length of the car. A schematic illustration of a generalized multi-level conventional railcar is shown in Figure 2.

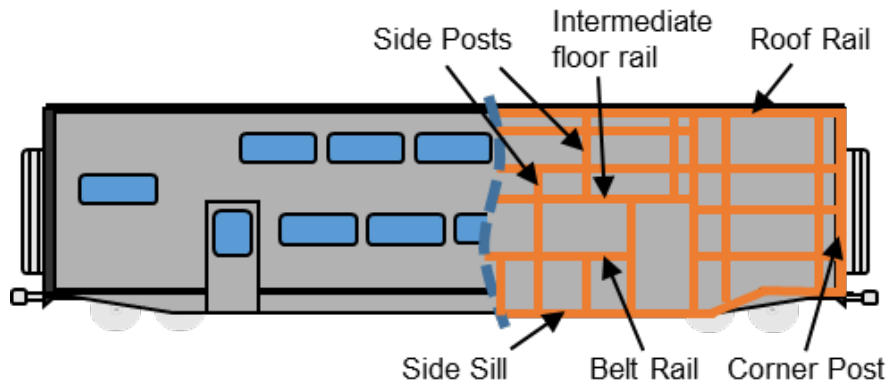

Figure 2. Generalized Sidewall Members, Multi-level Conventional Railcar

\section{ROLLING STOCK INVENTORY}

The current standards and regulations that address side structure integrity were issued in 1999. At the time of the rulemaking, the FRA stated that "most of the passenger cars in the United States possess floor structures similar to the Amfleet rail car, positioned at a similar height above the rail" [1]. The Amfleet rail car is a single-level railcar of conventional construction; thus, the fleet in 1999 was believed to be made up of mostly single-level railcars of conventional construction.

In the time since the 1999 rulemaking, new commuter rail operation start-ups have begun using new equipment designs, and railroads that existed at the time of the 1999 rulemaking have updated their rolling stock rosters. Therefore, it is important to understand whether the fleet makeup has changed significantly since 1999.

In particular, this study sought to determine whether the fleet was still comprised mostly of conventional single-level coaches, as described in the 1999 rulemaking, or whether multi-level or alternative designs had since become more prevalent. A 1996 report on passenger rail equipment suspension characteristics [4] included a car count as of January 1, 1994. The data from that car count were reviewed and, where necessary, adjusted based on current information. These data were used as a baseline and assumed to approximately represent the U.S. passenger railcar fleet at the time of the 1999 rulemaking.

In 2016, the authors performed a car count to reflect the stateof-the-fleet using publicly available rolling stock information from numerous sources. No railroads were contacted during this phase of the study, so these figures should be considered an approximate count of the entire fleet.

This count only included Tier I (operations at or below 125 $\mathrm{mph}$ ) passenger railcars operating on the general railroad system of the U.S. It did not include Tier II (operations between 125 and $150 \mathrm{mph}$ ) vehicles, privately-owned passenger cars, or Port Authority Trans-Hudson (PATH) equipment, as that railroad had been excluded from the 1994 car count. The cars identified in this count were grouped into three broad categories: (1) singlelevel railcars, (2) multi-level railcars, and (3) alternativelydesigned vehicles.

The 2016 car count identified 29 different railroad operators of passenger equipment in the U.S. The 1994 car count identified 14 railroads operating passenger equipment at that time. The 
estimated passenger railcar fleet is broken down by railcar type in Table 1 and Figure 3.

Table 1. Estimated Passenger Railcar Fleet in the U.S.

\begin{tabular}{ccc}
\hline Railcar Type & Count in 1994 & Count in 2016 \\
\hline Single-level & 4,472 & 4,367 \\
Multi-level & 1,875 & 3,254 \\
$\begin{array}{c}\text { Alternatively- } \\
\text { designed }\end{array}$ & 45 & 122 \\
\hline Total & 6,392 & 7,743 \\
\hline
\end{tabular}

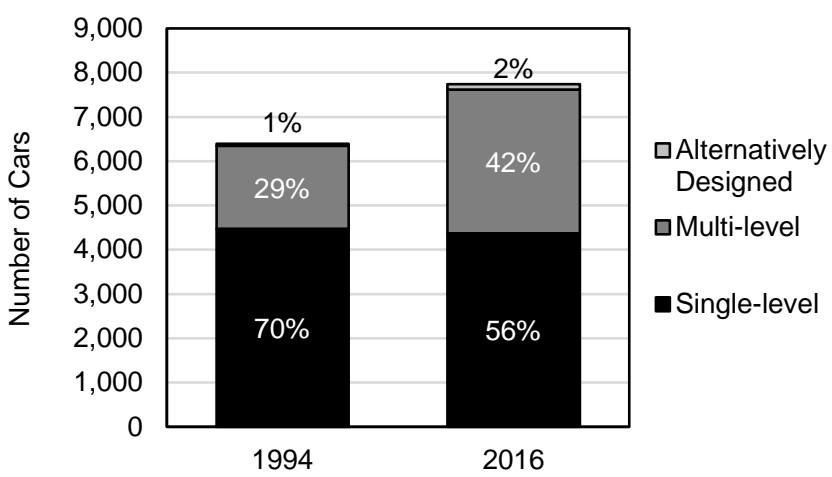

Figure 3. Estimated Passenger Railcar Fleet in the U.S.

These results indicate that since 1994 the passenger car fleet has grown by approximately 1,350 cars or $21 \%$. While the majority of the passenger fleet is still made up of single-level cars, the number of multi-level cars has nearly doubled since 1994 and now compromise approximately $42 \%$ of the passenger fleet. The increase in the number of multi-level cars indicates a need to ensure that current standards and regulations, some of which are based on longstanding design practice, remain relevant to the entire fleet. Thus, any new or modified criteria or evaluation procedures for side structure integrity should be relevant to both types of equipment. Additionally, because of the inherent structural differences between single- and multi-level passenger railcars, it is also important to consider whether a side impact presents the same hazard to each design.

\section{ACCIDENT HISTORY}

\section{Grade Crossing Accident Survey}

In the 1997 PESS Notice of Proposed Rulemaking (NPRM) [5] and Final Rulemaking [1], the FRA summarized the incidence of reported rail-highway grade crossing accidents using the publicly available Highway-Rail Accidents Database (6180.57) [6] from 1986 to 1995. While the exact figures that were reported at that time could not be replicated by the authors accessing the database approximately 20 years later, a summary is presented in Table 2 of grade crossing accidents involving passenger trains from 1986 to 1995 and in the following two decades to 2015.
Three categories of accidents are defined by filtering the grade crossing accident database: (1) the "all” category refers to grade crossing accidents involving a "passenger train" (TYPEQ $=2$ ) and a highway motor vehicle (TYPVEH = A - J); (2) the "side impact" category adds an additional filter for rail equipment struck by highway user (TYPACC $=2$ ); and (3) the "side impact from truck" category narrows the motor vehicle type filter to only include "truck" and "truck-trailer" (TYPVEH $=\mathrm{B}-\mathrm{C})$. It should be noted that "pick-up truck" (TYPVEH = D) was excluded from the last category with the intention of focusing on Heavy Duty Trucks such as a dump truck or semitrailer truck weighing over 33,000 pounds.

Table 2. Highway-Rail Grade Crossing Accidents Involving Passenger Trains and Highway Vehicles

\begin{tabular}{cccc}
\hline Years & All & Side Impact & $\begin{array}{c}\text { Side Impact } \\
\text { from Truck }\end{array}$ \\
\hline $1986-1995$ & 2,781 & $424(15.2 \%)$ & $107(3.8 \%)$ \\
$1996-2005$ & 2,287 & $262(11.5 \%)$ & $42(1.8 \%)$ \\
$2006-2015$ & 1,656 & $168(10.1 \%)$ & $21(1.3 \%)$ \\
\hline Total & 6,724 & $854(12.7 \%)$ & $170(2.5 \%)$ \\
\hline
\end{tabular}

It was observed that the frequency of reported grade crossing accidents involving passenger rail equipment decreased over the three decades included in the survey for every category. This decline in accident frequency is consistent with an overall trend with grade crossing accidents. The percentage of passenger train grade crossing accidents where the train was impacted by a "truck" or "truck-trailer” was also relatively low (2.5\%). It is also worth noting that only one accident (Miriam, NV) was reported between 1986 and 2015 where either railroad employees or passengers on a passenger train were killed in a side impact collision at a grade crossing.

\section{Focused Study of Side Impact Accidents}

A focused accident study on side impacts to rail vehicles as a major source of passenger equipment damage was also performed as a part of this research program. This study only includes accidents where the side impact was the primary event, such as a highway vehicle striking the side of a train at a grade crossing, as well as accidents where side impact occurred during a derailment subsequent to another primary incident.

The study includes accidents that have occurred both in the U.S. and in Canada. Canadian accidents were included in the study because railroad equipment operating on the general railroad system in Canada is structurally similar to equipment operated in the U.S. due to similar design requirements in both countries.

It is worth noting that relatively few accidents are included in this study. This list excludes accidents where the only engagement of the side structure is a passenger railcar coming to rest on its side as a result of a collision or derailment, as that 
situation (rollover) has requirements specified separately from side impact loads in the existing regulations and standards. In general, the primary sources for information on side impact incidents have been reports prepared by the NTSB or the Transportation Safety Board (TSB) of Canada. The NTSB and TSB do not investigate all minor incidents involving passenger rail equipment; thus, the results of the study are skewed toward more severe accidents which warranted the launch of a Safety Board investigation team.

The accident study is a useful tool for characterizing what types of impact scenarios tend to compromise the integrity of different railcar designs, i.e. single-level or multi-level. The results of the accident study also provide insight into the consequences of a side impact (e.g. tendency to derail, tendency to roll over, etc.) beyond localized side damage. Train derailments and rollovers tend to result in a large number of injuries as passengers experience a lateral acceleration relative to their surroundings and suffer secondary impacts with the car interior, so it is important to consider the potential for such an outcome during a side impact event. The results of the accident study are being used to plan future analysis research.

Table 3. Accident Study Involving Side Impact of Passenger Railcars

\begin{tabular}{lllll}
\hline Year & Location & \multicolumn{1}{c}{ Type of Incident } & \multicolumn{1}{c}{ Type of Rail Equipment } \\
\hline 1975 & Elwood, IL & Highway truck into passenger train & Amtrak Turboliner single-level cars \\
1999 & Hornepayne, Ontario & Passenger train into highway truck & VIA Rail single-level cars \\
1999 & Limehouse, Ontario & Passenger train into highway truck & Amtrak Superliner multi-level cars \\
2005 & Glendale, CA & Passenger train into passenger train & Metrolink multi-level cars & [8] \\
2006 & Franklin, MA & Passenger train into highway truck & MBTA multi-level cars \\
2007 & Woburn, MA & Passenger train into MOW equipment & MBTA single-level cars \\
2011 & Miriam, NV & Highway truck into passenger train & Amtrak Superliner multi-level cars \\
2013 & Cheat Mountain, WV & Highway truck into passenger train & WV Central Railroad single-level cars \\
2016 & Chester, PA & Passenger train into MOW equipment & Amtrak Amfleet cars \\
\hline
\end{tabular}

${ }^{\ddagger}$ Maintenance of way (MOW) equipment includes track maintenance equipment such as ballast regulators, tamping machines, etc.

In 1975, a highway dump truck traveling at approximately $35 \mathrm{mph}$ (while braking) struck the side of an Amtrak Turboliner train traveling at approximately $71 \mathrm{mph}$ in Elwood, IL [7]. The dump truck skidded and overturned during the impact event. A combination of the impact force and debris from the dump truck caused 4 out of 5 single-level coach cars to derail leading to injuries of 45 passengers but no fatalities. The collision is illustrated schematically in Figure 4.

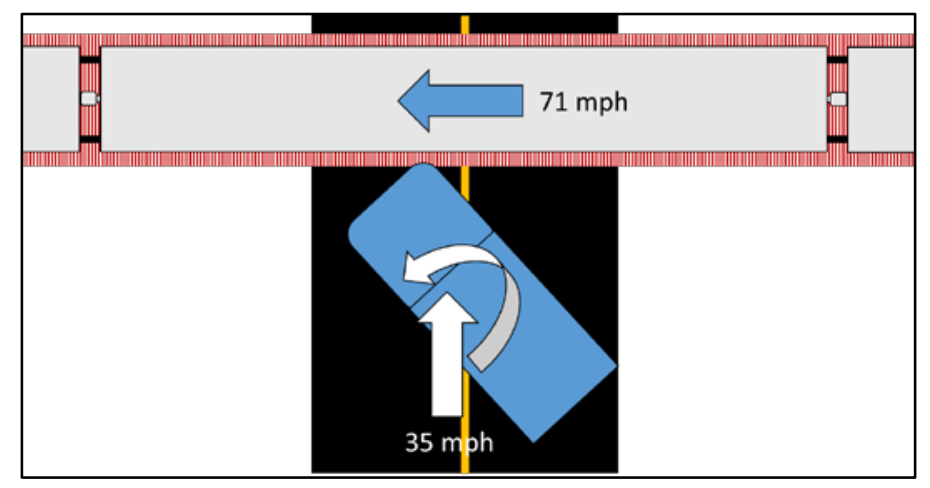

Figure 4. Schematic Illustration of Elwood, IL HighwayRail Accident
From the National Transportation Safety Board (NTSB) report on this accident, the damage to the train cars was described as

[i]mpact damage to the second car was restricted to the left rear side of the car... The damaged area was 24 feet 6 inches long, about 6 feet high, and about 8 inches deep at its deepest point. Two double-pane windows were shattered completely and a third had only its outer pane shattered. In the area of impact, the floor was deformed slightly, a pair of seats had rotated partially, and a folding tray was deformed to the right. The floor and seats were littered with broken window glass. There were no signs of side or roof panel buckling or deformation of the overhead baggage racks.

The third car was damaged at its left front corner. At that point, the lower-outside paneling had been crinkled and had been marked with horizontal striations, and the window was broken. The left front corner of the car was crushed beginning about 8 feet above the top of rail and extending upward for 21 feet. Some additional deformation occurred just above that crushed area. [7] 
In a similar accident in 2011, the sidewalls of two Amtrak Superliner multi-level railcars were breached in a highwayrailroad grade crossing collision in Miriam, NV [2]. A semitrailer truck pulling two unloaded side-dump trailers traveling at an estimated speed of 26-30 mph (while braking) impacted the side of the train which was traveling at $77 \mathrm{mph}$. The impact is illustrated schematically in Figure 5.

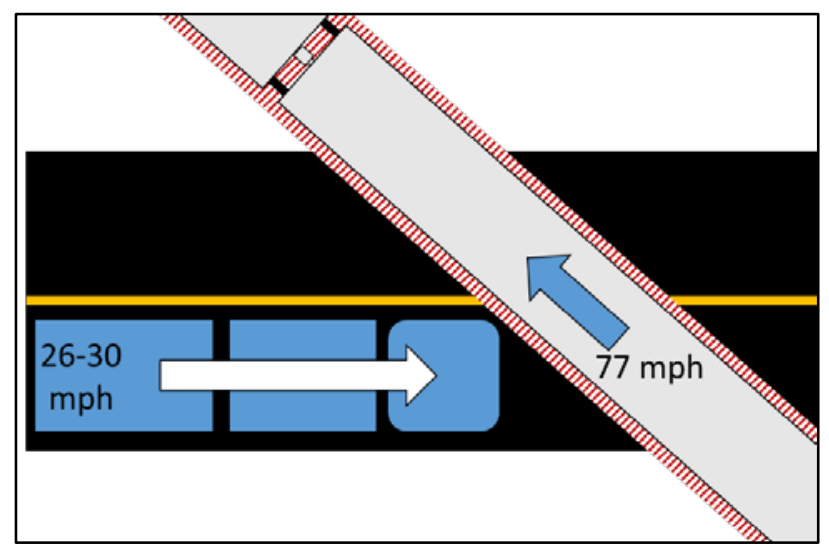

Figure 5. Schematic Illustration of Miriam, NV HighwayRail Accident

The highway vehicle impacted Amtrak Superliner Crew Sleeper Car 39013 at its lower level, and struck Coach Car 34033 on its upper level. The accident killed the driver of the semitrailer truck, the train conductor, and four train passengers; additionally, 15 train passengers and one train crewmember were injured. The two damaged sleeper cars are shown in Figure 6 and Figure 7.

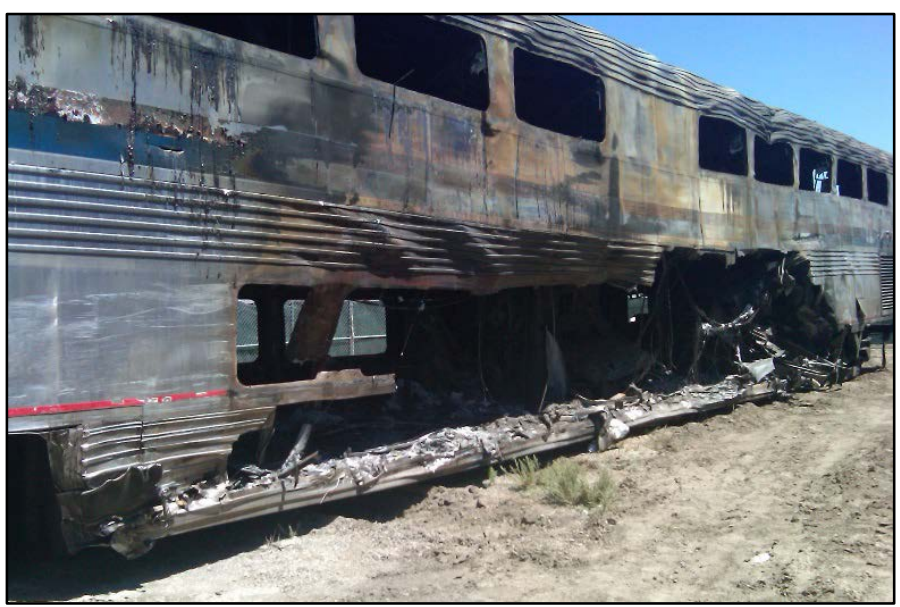

Figure 6. Sleeper Cars 39013 from Miriam, NV Accident Showing Damage from Highway Tractor Unit

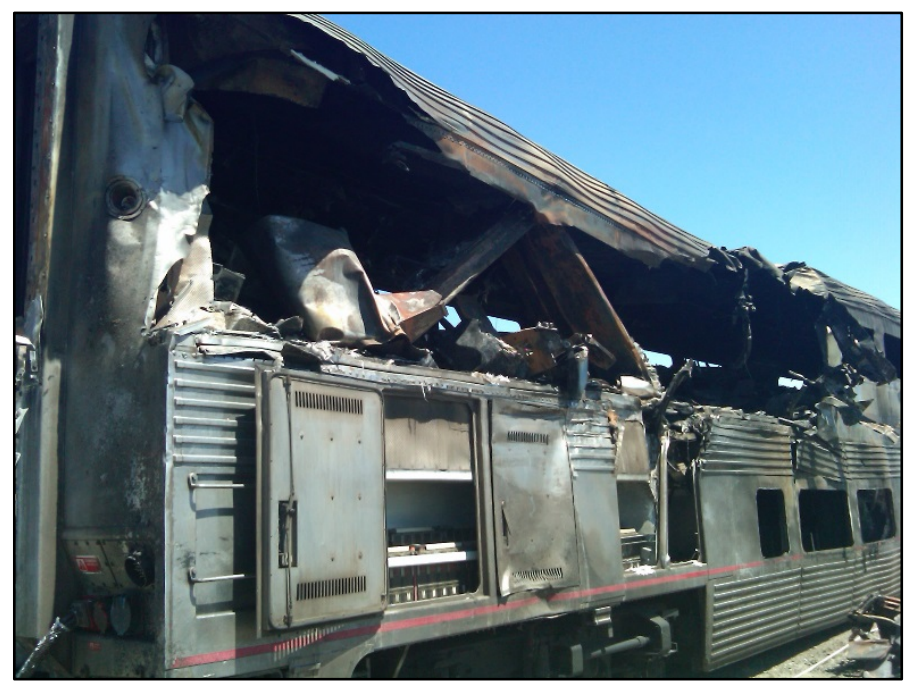

Figure 7. Coach Car 34033 from Miriam, NV Accident Showing Damage from Highway Trailer

In the NTSB's report on this accident [2] there is clear evidence that the engine compartment of the tractor unit overrode the side sill of car 39013, compromising the survival space of the passenger compartment. As the highway vehicle continued moving, the first side-dump trailer impacted the rear of the tractor unit and "ramped over" it. The trailer then collided and raked the upper level of the following railcar, car 34033. This led to a loss of survival space on the upper level of Car 34033, as seen in Figure 7. The passenger train did not derail in the Miriam accident and the multi-level railcars suffered a large loss of occupant survival space leading to cases of fatal blunt force trauma. Passengers outside of these impact zones suffered only minor injuries. In the Elwood accident, the train did derail without a large loss in occupant survival space; however, there was a larger number of non-life-threatening passenger injuries.

While these two accidents occurred under similar circumstances involving highway vehicles of similar masses impacting the trains at similar speeds, the outcomes were quite different. These accidents indicate the need to consider both the structural arrangement of the sidewall, including the height of the side sill or other major longitudinal members, and the postaccident kinematics (e.g. tendency to derail or rollover) of the struck railcar in evaluating potential improvements to overall occupant safety during side impact events.

\section{REGULATIONS AND STANDARDS}

Existing design criteria are described throughout this paper as derived from either a regulation or a standard. A regulation refers to a requirement promulgated through a federal rulemaking process that is required to be met for rail vehicles operating under the particular conditions applicable to the regulation. A standard refers to industry-adopted criteria and/or procedures that are non-compulsory, but may be required by a car buyer or railroad operating the equipment. 
Conventional U.S. practice for passenger railcar design was formalized as set of criteria and evaluation procedures first adopted by the Association of American Railroads (AAR) as recommended practices in 1939 [3]. Those practices were upgraded to a standard in 1945 (AAR S-034), last revised in 1969 (AAR-S-034-69), and discontinued in 1989.

As a longstanding design practice, the approaches used in AAR S-034-69 were largely adopted into subsequent regulations and standards. In 1999, both the FRA and the railroad industry, through the American Public Transportation Association (APTA), developed design criteria documents of their own. A timeline of standards and regulations development that include criteria for side structure design of passenger railcars in the U.S. is shown in Figure 8.

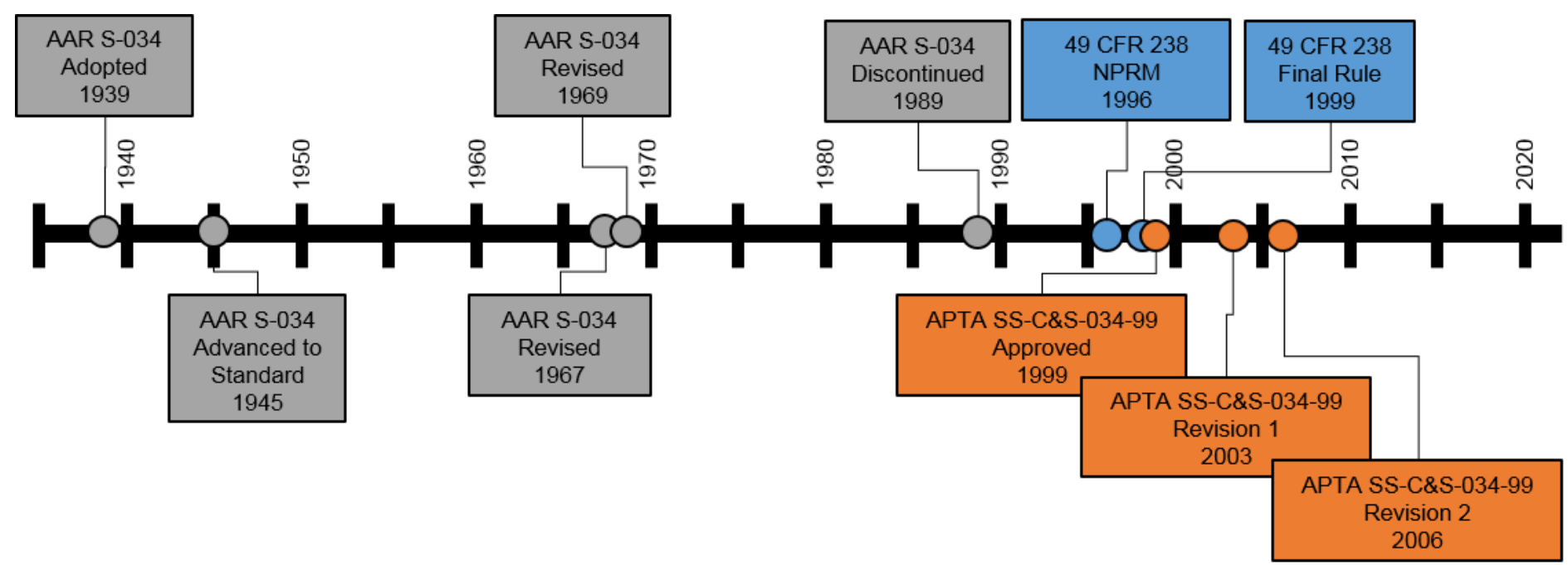

Figure 8. Timeline of Standards and Regulations Applicable to U.S. Railcars that Include Side Structure Criteria

\section{Rollover}

A passenger railcar rolling over and resting on its side is a load case that was not included in AAR S-034, but has been included in the FRA Tier I regulations (§238.215), FRA Tier II regulations (\$238.415), and APTA S-034-99. The requirements of these three current rollover standards and regulations are similar for passenger rail equipment. They specify that the car should be able to resist twice its weight while resting on its side as could occur after a derailment, and shown schematically in Figure 9. For single-level railcars, the railcar is supported at the longitudinal support members located at the roof (roof rail) and the bottom (side sill). For multi-level railcars, the railcar is supported at an additional longitudinal support member located at the intermediate floor.

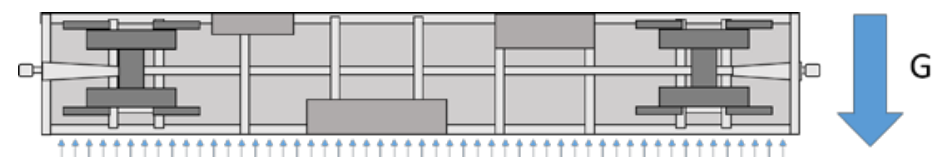

Figure 9. Schematic of Rollover Load Case, Carbody-onSide

Stresses in the structural support members must not exceed either half the yield stress $\left(\sigma_{Y}\right)$ or half the critical buckling stress $\left(\sigma_{C R}\right)$. This is similar to requiring the structural members to be able to withstand twice the weight of the car without reaching a critical stress value. The factor of 2 is an important safety factor since a dynamic rollover scenario, where a train is moving, would likely result in greater stresses than a rollover case with a stopped train.

Local yielding of the outer skin (sheathing) is allowed but not if it results in intrusion into the occupied volume of the car. The rollover requirement remains relevant, as an incident ending with a car resting on its side is a relatively frequent scenario [14, $15,16,17]$.

\section{Global Sidewall Stiffness}

AAR S-034-69 contained a requirement for sidewall stiffness where the sum of the section moduli of the sidewall posts at the weakest location in the sidewall were required to exceed a factor determined by the length of the sidewall multiplied by a constant. The requirement was applied to the section moduli calculated about a longitudinal and a transverse axis. Current Tier I equipment regulations (§238.217) and standards (APTA S-034-99) also contain similar requirements for vertical structural members. The existing design requirements essentially represent a global stiffness requirement for the entire sidewall.

In its 1999 rulemaking, the FRA stated:

This section $\$ 238.217$ was originally entitled "Side impact strength" in the NPRM [Notice of Proposed Rulemaking]. FRA has changed the section title because the requirements in this section principally refer to the stiffness of a car's side panel, rather than the panel's strength. That is, these 
provisions principally focus on preventing the side panel from flexing excessively under service loads. The greatest service loads acting on the sidewalls of a passenger car probably result from the aerodynamic loads of a train entering or exiting a tunnel, and from two trains passing each other at speed. Residually, these requirements will provide some protection in the event the passenger car's side panel is struck by an outside object [1].

Demonstrating compliance with the side structure stiffness requirement requires simple calculations based on the geometry of the sidewall and its material of construction. One major limitation of this global sidewall stiffness approach is that it is not directly apparent what measure of intrusion protection is provided by a sidewall designed to meet this requirement.

\section{Local Static Side Loads}

Local static side load requirements are specified in regulations for Tier II equipment (§238.417) and in the APTA S34-99 standard which applies to Tier I equipment. Local static side load requirements were not specified in AAR S-034-69, and were not adopted into FRA's Tier I regulations.

The Tier II side load requirements specify that the railcar structure should resist an inward transverse load of $80,000 \mathrm{lb}_{\mathrm{f}}$ applied to the side sill and $10,000 \mathrm{lb}_{\mathrm{f}}$ applied to the belt rail (horizontal members at the bottom of the window opening in the side frame) without exceeding either $\sigma_{Y}$ or $\sigma_{C R}$. Each load is applied separately over an $8 \mathrm{ft}$ length, and it is required that the structure withstand the loads regardless of where they are applied along the length of the carbody as seen in Figure 10. Note that while this figure shows multiple loads applied simultaneously, in practice each 8-foot section of belt rail or side sill would be evaluated individually.

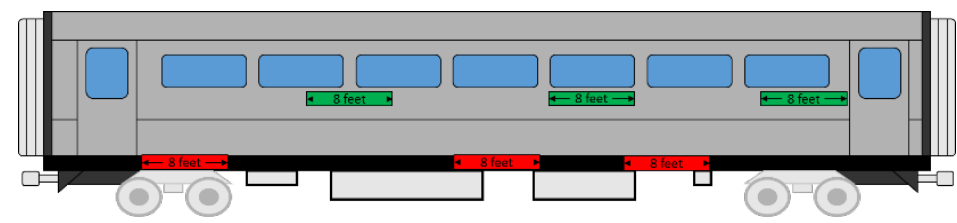

Figure 10. Schematic Illustration of 8-foot Side Sill and Belt Rail Loads showing Multiple Loading Positions
With respect to the Tier II side load requirements contained in §238.417, FRA stated in the 1999 rulemaking:

This section contains the requirements intended to resist penetration of the side structure of a passenger car by a highway or rail vehicle. The objective is to make the side of the passenger car strong enough so that the car derails rather than collapses when struck in the side by a highway or rail vehicle. If the passenger car can move sideways (derail), less structural damage and potential to injure train occupants will result. [5]

This statement makes it clear that that the side load requirements are intended to address side impact and preserve the occupant volume, and the 8 foot distance over which the loads are applied corresponds to the approximate width of a heavy highway truck bumper. However, it is not clear where the values for the $80,000 \mathrm{lb}_{\mathrm{f}}$ or $10,000 \mathrm{lb}_{\mathrm{f}}$ loads came from as their origin is not detailed in the Federal Register.

APTA S-034-99, which applies only to Tier I equipment, contains similar static side load cases that only differ in magnitude. The APTA standard requires a load of 40,000 $\mathrm{lb}_{\mathrm{f}}$ applied to the side sill and $7,000 \mathrm{lb}_{\mathrm{f}}$ applied to the belt rail. As a part of its discussion of the development of the side impact requirements, APTA states that FRA had requested the industry to consider developing side impact load requirements, suggesting a side impact scenario involving a highway tractortrailer. When the group was unable to reach consensus on a side impact scenario, the lateral belt rail and side sill loads were adopted as an alternative. APTA also states that "for the future, the APTA Construction and Structural Subgroup has committed to a more thorough investigation of the feasibility of designing rail vehicles for the FRA side impact scenario" [18].

A summary of the passenger rail equipment rollover and side structure integrity regulations and standards discussed in this section is presented in Table 4. 
Table 4. Summary of Passenger Railcar Side Structure Regulations and Standards

\begin{tabular}{|c|c|c|c|}
\hline Applicability & $\begin{array}{l}\text { Regulation or } \\
\text { Standard }\end{array}$ & Title & Description \\
\hline \multirow{2}{*}{ Tier I Regulation } & 49 CFR 238.215 & Rollover Strength & $\begin{array}{l}\text { Rest on (a) side or (b) roof } \\
\text { with } \sigma<\frac{\sigma_{Y}}{2} \text { and } \sigma<\frac{\sigma_{C R}}{2} \text { in frame }\end{array}$ \\
\hline & 49 CFR 238.217 & Side Structure & $\begin{array}{l}\text { Minimum section modulus / thickness and material } \\
\text { allowance }\end{array}$ \\
\hline \multirow{2}{*}{ Tier II Regulation } & 49 CFR 238.415 & Rollover Strength & $\begin{array}{c}\text { Rest on (a) side or (b) roof } \\
\text { with } \sigma<\frac{\sigma_{Y}}{2} \text { and } \sigma<\frac{\sigma_{C R}}{2} \text { in frame }\end{array}$ \\
\hline & 49 CFR 238.417 & Side Loads & $\begin{array}{l}\text { Static load } 80,000 \mathrm{lb}_{\mathrm{f}} \text { to side sill and } 10,000 \mathrm{lb}_{\mathrm{f}} \text { to belt rail } \\
\text { over } 8 \mathrm{ft} \text { with } \sigma<\sigma_{Y} \text { and } \sigma<\sigma_{C R} \text { in frame }\end{array}$ \\
\hline \multirow{2}{*}{$\begin{array}{l}\text { Historical Industry } \\
\text { Standard }\end{array}$} & \multirow{2}{*}{ AAR S-034-69 } & Side Posts and Bracing & Minimum section modulus and material allowance \\
\hline & & Sheathing & Minimum thickness and material allowance \\
\hline \multirow{3}{*}{$\begin{array}{l}\text { Current Industry } \\
\text { Standard }\end{array}$} & \multirow{3}{*}{$\begin{array}{l}\text { APTA PR-SS-C\&S- } \\
\text { 034-99, Rev. } 2\end{array}$} & Rollover Integrity & $\begin{array}{c}\text { Rest on side or roof } \\
\text { with } \sigma<\frac{\sigma_{Y}}{2} \text { and } \sigma<\frac{\sigma_{C R}}{2} \text { in frame }\end{array}$ \\
\hline & & $\begin{array}{l}\text { Side Structure } \\
\text { Framing \& Sheathing }\end{array}$ & $\begin{array}{l}\text { Minimum section modulus / thickness and material } \\
\text { allowance }\end{array}$ \\
\hline & & Side Impact & $\begin{array}{l}\text { Static load } 40,000 \mathrm{lb}_{\mathrm{f}} \text { to side sill and } 7,000 \mathrm{lb}_{\mathrm{f}} \text { to belt rail } \\
\text { with } \sigma<\sigma_{Y} \text { and } \sigma<\sigma_{C R} \text { in frame }\end{array}$ \\
\hline
\end{tabular}

Tier I speed $<125 \mathrm{mph}$; Tier II speed $>125 \mathrm{mph}$ and $<150 \mathrm{mph} ; \sigma_{Y}=$ Yield Stress; $\sigma_{C R}=$ Critical Buckling Stress

\section{Side Impact Assessment in Other Modes}

While not applicable to passenger railcars, this study considered existing side structure integrity evaluations for passenger vehicles used in other modes of transportation. This analysis sought to understand the working experience developed in the automobile industry in developing and applying sideimpact criteria and evaluation procedures that could be of benefit in evaluating passenger railcars under side impact conditions. In some ways, the standards and regulations for passenger railcars parallels those for passenger highway vehicles. The Insurance Institute for Highway Safety (IIHS) is an industry group that develops its own side structure criteria and evaluation procedures for automobiles, analogous to APTA's standards for passenger rail cars. Similar to the FRA, the National Highway Traffic Safety Administration (NHTSA) is a USDOT agency that promulgates mode-specific side structure integrity regulations.

\section{IIHS - Side Impact Test Protocol}

The IIHS has standardized crash test protocols for evaluating side impacts. Its test protocols are not requirements for any new vehicles. Rather, the IIHS performs its array of crash tests to derive safety ratings for different passenger vehicle designs and provides consumers with this information, which encourages manufacturers to produce safer vehicles to remain competitive.

The IIHS side impact test protocol [19] involves striking a stationary passenger car, light truck, or SUV with a specially designed moving deformable barrier (MDB) ram cart weighing 3,300 pounds, at a speed of $31.1 \mathrm{mph}$. This combination of mass and speed results in an impact with approximately 106,000 ft-lb of kinetic energy. In recognition of the tendency of the struck vehicle to overturn, pickup trucks and SUVs may have an "outrigger" added to the passenger side of the vehicle to limit the amount of roll the vehicle can undergo during the test.

The stationary car is instrumented, and two specialized sideimpact anthropomorphic test devices (ATDs), also known as test dummies, are positioned within the vehicle. IIHS determines its vehicle rating using a combination of injury criteria derived from dummy measurements and from measurements of the intrusion of the side pillar of the vehicle into the occupant volume.

\section{NHTSA - Side Impact Protection Regulation}

NHTSA's Federal Motor Vehicle Safety Standards (FMVSS) contain requirements for side impact testing to be performed on new passenger vehicles that meet particular criteria. These requirements are codified at 49 CFR 571.214 and must be met by relevant highway vehicles. The side impact requirements include quasi-static door crush resistance requirements, a dynamic side impact test using a MDB and side-impact ATDs, and a side impact into a rigid pole by a vehicle with side-impact ATDs inside.

The quasi-static door crush resistance test specifies an 18inch crush distance at a specific location on the door. The 
pass/fail criteria for these tests are required minimum average crush forces over the first 6 inches, over the first 12 inches, and over the entire crush distance.

The dynamic impact test uses a MDB vehicle weighing 3,015 pounds at a speed of $33.5 \mathrm{mph}$. This combination of mass and speed results in an impact with approximately 113,000 ft-lb $\mathrm{b}_{\mathrm{f}}$ of kinetic energy. The dynamic side impact test does not include any requirements or limitations on intrusion into the occupied volume. The criteria do include limitations on door separation. This test's pass-fail criteria are based upon ATD measurements. The test protocol defines upper limits on various injury criteria, and the measurements from the ATDs must be shown to not exceed these criteria.

The 16 - 20 mph side impact pole test does not include any requirements or limitations on intrusion into the occupied volume. The criteria do include limitations on door separation. This test's pass-fail criteria are based upon advanced ATD measurements. The test protocol defines upper limits on various injury criteria, and the measurements from the ATDs must be shown to not exceed these criteria.

The NHTSA and IIHS approaches differ in that IIHS uses a single test to examine both the injury criteria obtained through ATD measurements as well as the structural response through intrusion measurements. NHTSA measures resistance to intrusion through its door crush test, and measures ATD response in the moving deformable barrier side impact test and the pole test. While both NHTSA and the IIHS have dynamic side impact tests, the specific test vehicles, their orientations, and the test protocols are not identical.

No direct comparison can be made between passenger highway vehicles and passenger rail equipment with respect to side structure design and performance criteria. However, the approach taken in implementing quasi-static and dynamic side structure test protocols while quantifying intrusion into the occupied volume is informative for planning the analyses in the next phase of this study.

\section{ANALYSIS PLANS}

The planned next phase of this research project will involve analyses of generalized side structures of passenger railcars to better understand how different railcar designs that meet the existing side structure criteria perform under loading conditions which differ from those in the current regulations and standards. Several technical challenges exist to improving the side structure integrity of passenger rail vehicles that are subjected to significant impact loads.

During a side impact to a passenger railcar, the lateral loads acting on the carbody will act both to deform (indent) the side of the car, and to deflect the center of gravity of the car in the direction the impacting object is traveling. Depending on the height of the impact, the structural details of the railcar's design (including mass distribution), and the railcar's suspension characteristics, a lateral force can result in both a tendency to shift the carbody laterally and to cause the carbody to roll about its longitudinal axis.
How a given lateral load is reacted by some combination of wheel-rail interaction or the coupling mechanism will depend on the duration of the impact event, the location of the impact (both the height and the position along the length of the car), the speed of the moving train, the structural design of the carbody, the suspension design, and the details of the car-to-car connection. Further investigation of the influence of these different factors is planned as a part of this research program.

In general, the energy absorbed through deformation of a body is a function of the applied force and the amount of deformation. In the case of a side impact, the kinetic energy of the impacting object will be partially dissipated through crush of the sidewall structure. The energy-absorbing capacity of a structure, such as the sidewall, may be improved by increasing the average force required to crush that structure by a prescribed distance, by increasing the crushable distance for a fixed force, or simultaneously increasing both the force and the crush distance.

However, there are practical limits to each of these approaches. If a sidewall structure is constructed such that it allows a very small amount of inward deformation (relatively stiff) and can sustain a higher force without structural failure, the energy absorbing capacity of the sidewall will be increased. However, the higher lateral force applied to the carbody may result in an increased tendency toward derailment and/or rollover. While the occupied volume would be maintained during the initial impact, the resulting derailment and/or rollover introduces additional hazards to the occupants of the railcar, such as non-compartmentalized impacts with the interior, free-flying objects or debris within the car, and potential threats to the nonstruck side of the coach associated with it rolling over (e.g. rolling down an embankment, rolling onto a hazardous structure, etc.). This research program plans to investigate the lateral forces necessary to cause rollover for different generalized carbody designs and suspension designs to estimate bounds for the lateral forces that can reasonably be expected to be sustained by a sidewall before derailment and/or rollover becomes likely.

Energy absorption can also be increased by designing a structure that has a modest crush force and increasing the allowable crush distance over which that force may act. By limiting the force that is applied laterally, the risk of derailment or rollover is also limited. However, the allowable space for crushing the sidewall of the car is also limited. From the earliest stages of FRA's passenger equipment research, the primary objective of crashworthy design "is to preserve a sufficient occupant volume for the occupants to ride out the collision without being crushed, thrown from the train, or directly struck from something outside the train" [20]. This concern for maintaining sufficient survival space is extremely relevant in the event of side impacts, as seats are typically attached directly to the sidewall of the carbody. This offers a very limited amount of crushable space before the occupied volume of the car begins to reduce.

The challenge of limiting occupied volume intrusion is not unique to protecting rail passengers during side impacts. In 
describing its side impact testing program, the IIHS has written that "[p]rotecting people in side crashes is challenging because the sides of vehicles have relatively little space to absorb energy and shield occupants, unlike the fronts and rears, which have substantial crumple zones" [19]. IIHS bases its side impact safety ratings of passenger vehicles on a series of injury criteria derived from ATDs as well as the residual deformation of the side of the vehicle into the occupied volume in a standardized impact scenario. Thus, the IIHS approach considers both the intrusion into the occupied volume as well as the injuries sustained by the occupants during the impact.

The indentation of the sidewall of a passenger highway or rail vehicle is a function of the structural design of the vehicle. The IIHS's rating system for occupied volume intrusion measures the distance between the point of maximum intrusion of the B-pillar (pillar between front and rear doors) of the struck vehicle and the centerline of the driver's seat. The smaller the distance between the center of the seat and the pillar (meaning the largest loss of occupied volume), the poorer the rating for the structural portion of the vehicle assessment.

As a part of the next stage of this research program, the strategy for assessing occupied volume intrusion used by IIHS will be considered to better understand how generalized sidewall structures may deform under different loading or impact scenarios. By combining the estimated lateral forces necessary to result in derailment, and the maximum indentation allowed by the IIHS protocol (as applied to a passenger railcar), the energy absorption capacities of sidewalls can be estimated. These energies can also be compared with the kinetic energies of different combinations of impacting vehicles and impact speeds. By examining the relationships between sidewall crush, rail vehicle rollover, and striking object kinetic energy, it is hoped that a practical range of side impact scenarios can be defined.

\section{CONCLUDING REMARKS}

Research is currently underway to evaluate the side impact performance of passenger railcars. In the first phase of this research program the current state of passenger railcar side structure design was examined through a study of accidents involving side structures, a review of the current standards and regulations governing side structure was performed, and an estimate of how the passenger railcar fleet in the U.S. has changed since the existing regulations were developed. The results of this phase will be used to guide the development of an analysis plan to investigate alternative side structure loading scenarios. The analysis phase is expected to include consideration of the force-versus-crush behaviors of generalized passenger railcar side structures subjected to different impacts, the relationship between impact force and derailment or rollover potential, and consideration of practical limits on the inward deflection of sidewalls under impact conditions.

\section{ACKNOWLEDGMENTS}

This work was performed under the FRA Office of Research, Development, and Technology Equipment Safety Research
Program. The authors would like to thank the program manager, Jeff Gordon. The authors would also like to thank Bernard Kennedy at the Volpe National Transportation Systems Center for his assistance in conducting the rolling stock inventory.

\section{REFERENCES}

[1] Federal Register, "Passenger Equipment Safety Standards (PESS)," 64 FR 25540-25705, May 12, 1999.

[2] National Transportation Safety Board, "HighwayRailroad Grade Crossing collision US Highway 95 Miriam, Nevada June 24, 2011," NTSB/HAR-12/03, December 11, 2011.

[3] Association of American Railroads, "Sepcification for the Construction of New Passenger Equipment Cars," AAR S-034-69, Adopted 1939, Revised 1969.

[4] A. Bing, S. Berry and H. Henderson, "Design Data on Suspension Systems of Selected Rail Passenger Cars," DOT/FRA/ORD-96-01, July 1996.

[5] Federal Register, "Passenger Equipment Safety Standards (PESS)," 62 FR 49728-49824, September 23, 1997.

[6] Federal Railroad Administration Office of Safety Analysis, "Highway Rail Accident Database (6180.57)," [Online].

Available: https://safetydata.fra.dot.gov/OfficeofSafety/publicsite/o n_the_fly_download.aspx.

[7] National Transportation Safety Board, "Collision of a Crown-Trygg Construction Company Truck with an Amtrak Passenger Train in Elwood, Illinois on November 19, 1975," NTSB-RHR-76-2, May 12, 1976.

[8] Transportation Safety Board of Canada, "Collision at Crossing, VIA Rail Canada, Inc., Train No. 2, Mile 290.50, Ruel Subdivision in Hornepayne, Ontario on July 14, 1999.," R99H00009.

[9] Transportation Safety Board of Canada, "Crossing Collision/Derailment, VIA Rail Canada Inc., Passenger Train No. 85, Mile 33.54, Goderich-Exeter Railway (GEXR) Guelph Subdivision in Limehouse Ontario on November 9, 1999," R99S0100.

[10] D. Parent, D. Tyrell, K. Jacobsen and K. Severson, "Crashworthiness Analysis of hte January 26, 2005 Glendale, California Rail Collision," in Joint Rail Conference, JRC2011-561332, Pueblo, CO, 2011.

[11] Federal Railroad Administration Office of Safety Headquarters, "Accident Investigation Report Massachusetts Bay Commuter Railroad Company in Franklin, MA on October 23, 2006," HQ-2006-83.

[12] National Transportation Safety Board, "Collision of Massachusetts Bay Transportation Authority Train 322 and Track Maintenance Equipment near Woburn, MA on January 9, 2007," NTSB/RAR-08/01, May 18, 2008. 
[13] National Transportation Safety Board, "Preliminary Report: Railroad DCA16FR007," April 18, 2016.

[14] National Transportation Safety Board, "Amtrak Train Derailment on BNSF Railway Track in Cimarron, Kansas on March 13, 2016," RAB1710.

[15] National Transportation Safety Board, "Derailment of Amtrak Passenger Train 188 in Philadelphia, PA on May 12, 2015," RAR1602.

[16] National Transportation Safety Board, "Metro-North Railroad Derailment in Bronx, NY on July 18, 2013," RAB1411.

[17] National Transportation Safety Board, "Train and Truck Crash on Railroad Right-of-Way and Subsequent Fire in Oxnard, CA on February 24, 2015," HAB1607.
[18] American Public Transportation Association, "Standard for the Design and Construction of Passeneger Railroad Rolling Stock," APTA PR-CS-S-034-99, Rev. 2, June 11, 2006.

[19] Insurance Institute for Highway Safety, "Side Impact Crashworthiness Evaluation Crash Test Protocol (Version X)," July 2017.

[20] D. Tyrell, K. Severson and B. Marquis, "Train Crashworthiness Design for Occupant Survivability," in ASME IMECE AMD Vol. 210/BED Vol. 30, San Francisco, CA, November 1995. 